UDC: 339.743

JEL Classification: F32, F33

Keywords: exchange rate regime, capital account, structural vector autoregression

\title{
Pick Your Poison: The Exchange Rate Regime and Capital Account Volatility in Emerging Markets
}

Shigeru IWATA - Department of Economics University of Kansas (iwata@ku.edu)

Evan TANNER - International Monetary Fund / IMF Institute (etanner@imf.org)

\section{Abstract}

We characterize a country's exchange rate regime by how its central bank channels a capital account shock across three variables: exchange depreciation, interest rates, and international reserve flows. Structural vector autoregression estimates for Brazil, Mexico, and Turkey reveal such responses, both contemporaneously and over time. Capital account shocks are further shown to affect output growth and inflation. The nature and magnitude of these effects may depend on the exchange rate regime.

\section{Introduction}

"There was huge ambivalence on the part of the staff (regarding policy options for Asian countries facing capital outflows) [...] if we jack up interest rates, we will kill off our companies. But, you are dealing with a foreign exchange crisis. So pick your poison. You are going to have a terrible problem either way."

Karin Lissakers, U.S. Representative to the IMF, quoted in (Blustein, 2001, p. 156, emphasis added).

The choice of exchange rate regime is a perennial issue for policymakers. But, in the wake of the recent volatility in global capital markets, this issue has taken on special relevance for emerging markets. ${ }^{1}$ Recent exchange rate crises have led some to conclude that, in an environment of capital market volatility, more exchange rate flexibility is desirable. ${ }^{2}$

Unfortunately, accepting more exchange rate flexibility can also represent a choice among undesirable alternatives: facing an adverse shock, central banks must "pick their poison". Letting the currency depreciate, they have to accept unwanted effects such as additional price inflation and adverse balance sheet effects on foreign currency financial liabilities. Raising the interest rate to defend the exchange rate, on the other hand, may adversely affect economic activity, financial sector balance sheets, or both.

An exchange rate regime should ultimately reflect a central bank's preference as to how such a shock should be transmitted to the domestic economy. However,

\footnotetext{
${ }^{1}$ This paper is primarily positive and empirical. Normative, theoretical papers on the choice of exchange rate regime are too numerous to mention. Recent theoretical papers that link exchange rate regimes to volatile external capital markets, domestic output, and inflation include (Lahiri, Végh, 2001) and (Parrado, Velasco, 2002).

${ }^{2}$ Stanley Fischer (2001) suggests that since traditional (soft) pegs are unsustainable in such an environment, exchange rate regimes have instead drifted towards the polar extremes of either hard pegs or free floats. On this issue, see also (Edwards, Savastano, 1999) and (Edwards, 2000).
} 
ascertaining the regime actually chosen by the central bank or how such shocks affect the domestic economy can be a difficult task. As is well known, a country's stated exchange rate policy can differ substantially from its actual one, as observed by Levy-Yeyati and Sturzenegger (2005), Bubula and Otker-Robe (2002), and Reinhart and Rogoff (2004) among others. ${ }^{3}$ Moreover, exactly how to measure the exchange rate regime - that is, the degree of flexibility - remains an open question, which will be discussed in greater detail below.

This paper examines a country's choice of exchange rate regimes and their effect on the economies in emerging markets. ${ }^{4}$ First, we empirically characterize a country's exchange rate regime as a dynamic response to external capital account shocks ${ }^{5}$ - how countries "pick their poison". Second, we analyze the impact of capital market shocks on the domestic economy when it chooses a particular response - the outcome of the "poison". Specifically, we assess the effect of such shocks on two key domestic variables: real economic growth and inflation, conditional on an exchange rate regime chosen by the central bank. In this way, we can evaluate how - if at all the choice of exchange rate regime affects the outcome of external shocks to the domestic economy. ${ }^{6}$

More specifically, our model casts this policy decision in two dimensions. In one dimension, the central bank decides whether to adjust monetary aggregates (reserves, with corresponding domestic credit flows) or prices (exchange rates, interest rates), or some combination thereof. In the other dimension, the central bank decides which of the prices to adjust: interest rates, exchange rates, or some combination thereof. When central banks aim to shield domestic economies from such shocks, they typically do so by limiting both exchange rate and interest rate flexibility. As a result, the shock is partly absorbed by international reserve flows, which may in turn be offset to some degree by domestic credit creation through sterilized intervention. Such a policy may be unsustainable, but interest rate and exchange rate flexibility may also be undesirable.

We use a structural vector autoregression (SVAR) framework. Doing so permits us to analyze how a single shock might be channeled into several variables. We examine impulse response functions (IRFs) of capital market shocks on these domestic variables across different time periods and exchange rate regimes. We also investigate simulated IRFs based on counterfactual exchange rate regime assumptions.

The results in this paper help illustrate a variety of exchange rate/monetary regimes. At one extreme, in Mexico, prior to its crisis of late 1994, external shocks were nearly completely reflected in reserve flows. By contrast, in Turkey, from mid-

\footnotetext{
${ }^{3}$ The standard reference on nominal or declared exchange rate regimes is the International Monetary Fund's Annual Report on Exchange Arrangements and Exchange Restrictions. As a point of comparison, these authors develop several measures of effective exchange rate policy.

${ }^{4}$ They are Brazil, Mexico, and Turkey, which have recently faced several kinds of external shocks, including those to the capital account.

${ }^{5}$ Calvo, Leiderman, and Reinhart (1993) examine the impact of reserve shocks on domestic variables.

${ }^{6}$ Levy-Yeyati and Sturzenegger (2002) propose to gauge exchange rate policy by examining exchange rate volatility, both unconditionally and relative to the sum of the variances of exchange rates and reserves (a bivariate measure of exchange market pressure). Unfortunately, such indices ignore the essential nature of an exchange rate regime as a response to a shock.
} 
-1994 through 2001 (just before an exchange rate crisis) the central bank responded to external shocks primarily with interest rate movements.

The rest of this paper is organized as follows. In Section II, the SVAR model and its identifying restrictions are developed. Section III presents the empirical results, including effects of capital market shocks on the domestic economy. Section IV presents the simulation analysis mentioned above. Section V provides a summary and conclusions.

\section{A Structural Vector Autoregression (SVAR) Approach}

Central banks in emerging market (EM) economies face several factors that distinguish them from industrialized countries. First, emerging market economies are typically subject to substantial external shocks. Such shocks may reflect business cycles and monetary policy in industrialized countries, perceived investor risk, exchange rate risk, and market contagion. ${ }^{7}$ Second, emerging market assets are poor substitutes with, and generally riskier than, those from industrialized countries. Third, emerging market central banks intervene in foreign exchange markets to much larger a degree than in most industrialized countries. In this context, the central bank is assumed to channels external capital account shocks into three variables, namely international reserve, interest rate, and exchange rate adjustment.

This section lays out a structural vector autoregression (SVAR) model of central bank's behavior in an emerging market economy. In Section 2.1, the basic SVAR model is developed. Section 2.2 presents the identifying assumptions. Section 2.3 provides a detailed discussion about the central bank's response to external capital account shocks.

\section{I The Basic Model}

Consider a vector of observed variables $\boldsymbol{X} .{ }^{8}$ We partition this vector into two subvectors: $\boldsymbol{X}^{n}$ and $\boldsymbol{X}^{\boldsymbol{m}}$. The vector $\boldsymbol{X}^{n}$ contains broader macroeconomic ("non-monetary") variables: output growth $(Y)$, inflation $(P)$, and the fiscal deficit (scaled by the monetary base) $(F){ }^{9}$ The vector $\boldsymbol{X}^{\boldsymbol{m}}$ represents a set of "monetary" and financial variables, including changes in net foreign reserves $(N)$ and domestic credit $(D),{ }^{10}$ the interest rate $(R)$ and nominal exchange depreciation $(E)$. The model also includes the terms of trade $(T)$ and the dollar (London interbank) interest rate $\left(R^{*}\right)$ as the exogenous variables on the right hand side. ${ }^{11}$ The reduced form system is:

$$
X_{t}=c_{0}+C_{1} X_{t-1}+\ldots+C_{p} X_{t-p}+C_{0}{ }^{*} Z_{t}+\ldots+C_{q}{ }^{*} Z_{t-q}+u_{t}
$$

where $\boldsymbol{X}_{\boldsymbol{t}}=\left[\boldsymbol{X}_{\boldsymbol{t}}^{\boldsymbol{n}}, \boldsymbol{X}_{\boldsymbol{t}}^{\boldsymbol{m}} \boldsymbol{\prime}\right]$ ', $\boldsymbol{X}_{\boldsymbol{t}}^{\boldsymbol{n}}=\left[Y_{t}, P_{t}, F_{t}\right]^{\prime}, \boldsymbol{X}_{t}^{m}=\left[N_{t}, D_{t}, R_{t}, E_{t}\right]^{\prime}, \boldsymbol{Z}_{\boldsymbol{t}}=\left[T_{t}, R_{t}^{*}\right]^{\prime}, \boldsymbol{c}_{0}$ is

\footnotetext{
${ }^{7}$ Several authors, including Calvo, Leiderman, and Reinhart (1993) and Fernandez-Arias (1996), suggest that capital flows to and from less industrialized countries are primarily due to exogenous (or "push") factors.

${ }^{8}$ The construction of all variables is detailed in the Appendix.

${ }^{9}$ Scaling the deficit in this way reflects the fact that base money is often the residual financing source for an emerging market government. Note also that the primary (noninterest) deficit is used.

${ }^{10}$ Net foreign reserves and domestic credit are both scaled by base money so that their sum is equal to the growth rate of monetary base, consistent with the traditional monetary approach to the balance of payments. Also, such a scaling has an intuitive interpretation vis-à-vis fiscal policy, insofar as the base money is the source of seignorage for the public sector.
} 
a vector of constants, $\boldsymbol{C}_{i}$ are matrices of the coefficients on the lagged endogenous variables

$\boldsymbol{X}_{t-i}(i=1,2, \ldots, p), \boldsymbol{C}_{j}^{*}$ is a matrix of the coefficients on the current as well as lagged exogenous variables $\boldsymbol{Z}_{t-j}(j=0,1, \ldots, q)$, and $\boldsymbol{u}_{t}$ is a vector of the one-step-ahead forecast errors. The reduced form errors $\boldsymbol{u}_{t}$ are related to the structural shocks $\boldsymbol{e}_{t}$ according to:

$$
\boldsymbol{u}_{t}=\boldsymbol{B} \boldsymbol{e}_{t}
$$

where $\boldsymbol{E}\left(\boldsymbol{e}_{\boldsymbol{t}}\right)=0$ and $\operatorname{Cov}\left(e_{t}\right)=\boldsymbol{D}$, which is diagonal. The structural model is given by

$$
A \boldsymbol{X}_{t}=\boldsymbol{a}_{0}+\boldsymbol{A}_{1} \boldsymbol{X}_{t-1}+\ldots+\boldsymbol{A}_{p} \boldsymbol{X}_{t-p}+\boldsymbol{A}_{0}{ }^{*} \boldsymbol{Z}_{t}+\ldots+\boldsymbol{A}_{q}{ }^{*} \boldsymbol{Z}_{t-q}+\boldsymbol{e}_{t}
$$

where $A=\boldsymbol{B}^{-1}$. There are seven structural shocks: the aggregate supply shock $\left(e_{A S}\right)$, the aggregate demand shock $\left(e_{A D}\right)$, the fiscal shock $\left(e_{F}\right)$, the external (capital account) shock $\left(e_{N}\right)$, the money supply shock $\left(e_{M S}\right)$, the money demand shock $\left(e_{M D}\right)$, and the exchange rate shock $\left(e_{E}\right)$. We conformably partition $\boldsymbol{u}_{t}$ and $\boldsymbol{e}_{t}$ into the non-monetary and monetary components:

$$
u_{t}=\left[u^{n \prime}, u^{m \prime}\right] ' \text { and } e_{t}=\left[e_{t}^{n '}, e_{t}^{m \prime}\right]
$$

where $\boldsymbol{u}_{\boldsymbol{t}}{ }^{\boldsymbol{1}}=\left[u_{Y t}, u_{P t}, u_{F t}\right]^{\prime}$,

$$
\boldsymbol{u}_{\boldsymbol{t}}^{\boldsymbol{m}}=\left[u_{N t}, u_{D t}, u_{R t}, u_{E t}\right]^{\prime}, \boldsymbol{e}_{\boldsymbol{t}}^{\boldsymbol{n}}=\left[e_{A S t}, e_{A D t}, e_{F t}\right]^{\prime} \text {, and } \boldsymbol{e}_{t}^{n}=\left[e_{N t}, e_{M S t}, e_{M D t}, e_{E t}\right]^{\prime}
$$

Similarly, $\boldsymbol{B}$ may be partitioned as:

$$
B=\left[\begin{array}{ll}
B^{n n} & B^{n m} \\
B^{m n} & B^{m m}
\end{array}\right]
$$

\subsection{Identification}

The identification scheme rests on five key assumptions. ${ }^{12}$ First, output growth, inflation, and the fiscal deficit are assumed to respond to the monetary and financial shocks $\left(e_{N}, e_{M S}, e_{M D}, e_{E}\right)$ with a delay. Thus, $\boldsymbol{B}^{n \boldsymbol{m}}=0$. Second, output growth does not respond to either the aggregate demand shock or the fiscal shock contemporaneously. Likewise, inflation does not respond to the fiscal shock contemporaneously. Jointly, these assumptions imply that matrix $\boldsymbol{B}^{\boldsymbol{n} \boldsymbol{n}}$ is lower triangular. The lagged responses implied by the first two assumptions plausibly reflect delays in the production process and price rigidities for a monthly dataset.

Third, the external capital account shock $e_{N}$ has non-zero effects on all variables in monetary and financial block. Such a shock reflects perceived investment (default) risk, exchange rate risk, and market contagion. ${ }^{13}$ The central bank responds to such a shock according to the following cross-equation restrictions:

\footnotetext{
${ }^{11}$ Terms of trade are available for Brazil and Mexico. For Turkey, the dollar price of petroleum is used. While this practice follows Kim and Roubini (2000) and others, results may not be strictly comparable across countries. Note also that we use the industrial production index as a monthly proxy for gross domestic product (see Appendix). Such a proxy is imperfect: it captures only a fraction of, and is not always closely correlated with, overall output. Also, to test for industrial country business cycle effects, the regressions were also run with a monthly index of production from industrialized countries. The results (not reported here) were almost identical to those presented in this paper.

12 The restrictions presented in this section ensure that the model is just identified.
} 


$$
\left[\begin{array}{l}
b_{N N} \\
b_{D N} \\
b_{R N} \\
b_{E N}
\end{array}\right]=\left[\begin{array}{c}
\lambda \\
\lambda \alpha \\
-(1-\lambda) \beta \\
-(1-\lambda)(1-\beta)
\end{array}\right]
$$

Fourth, the money demand term $e_{M D}$ reflect exogenous shocks in domestic money holding behavior. These shocks are orthogonal to $e_{N}$ and thus do not enter in contemporaneous reaction functions for either international reserves or domestic credit. In a similar vein, the exchange shock $e_{E}$ reflects idiosyncratic exchange rate policy, likewise orthogonal to $e_{N}$. Accordingly, this shock is also excluded from contemporaneous reaction functions for international reserves, domestic credit, or the interest rate.

Fifth, fiscal shocks are assumed to have no direct contemporaneous effects on international reserves. Such shocks will have indirect impacts through the domestic credit channel: innovations to the public deficit contemporaneously affect international reserves if only they are financed with domestic money creation.

The intuition behind these restrictions is fully explained in the next section. The above assumptions together with their appropriate normalizations imply that the matrix $\boldsymbol{B}$ is:

$$
\boldsymbol{B}=\left[\begin{array}{lllllll}
1 & 0 & 0 & 0 & 0 & 0 & 0 \\
b_{P A S} & 1 & 0 & 0 & 0 & 0 & 0 \\
b_{F A S} & b_{F A D} & 1 & 0 & 0 & 0 & 0 \\
b_{N A S} & b_{N A D} & 0 & b_{N N} & b_{N M S} & 0 & 0 \\
b_{D A S} & b_{D A D} & b_{D F} & b_{D N} & 1 & 0 & 0 \\
b_{R A S} & b_{R A D} & b_{R F} & b_{R N} & b_{R M S} & 1 & 0 \\
b_{E A S} & b_{E A D} & b_{E F} & b_{E N} & b_{E M S} & b_{E M D} & 1
\end{array}\right]
$$

Thus coefficients in $\boldsymbol{B}$ matrix are estimated subject to both the cross-equation restrictions in (4) and the zero-restrictions in (5).

\subsection{How Does the Central Bank Channel an External Capital Market Shock $\left(e_{N}\right)$ ?}

Our modeling strategy rests on two key ideas. First, the shock $e_{N}$ summarizes all external capital market shocks to which the central bank must react. Second, the central bank faces a constraint: the entirety of such a shock must be channeled into three

\footnotetext{
${ }^{13}$ Note that the shock term $e_{N}$ resembles in some ways several commonly-used indices of exchange market pressure (EMP) that are based on seminal work by Girton and Roper (1977) (see also (Eichengreen, Rose, Wyplosz, 1996), (Sachs, Tornell, Velasco, 1996), and (Tanner, 2000)). Both $e_{N}$ and EMP are weighted averages of reserve movements, interest differentials, and exchange rate depreciation. Another widely used measure of external pressures faced by a country is the emerging market bond index (EMBI). Our measure has several advantages over the EMBI, however. First, EMBI is a spread between two dollar-denominated interest rates. Therefore, unlike our measure, the EMBI reflects country risk but not exchange risk per se. Second, unlike the EMBI, our measure directly reflects the balance of payments constraint faced by the central bank.
} 
variables: international reserves, interest rates, and exchange rates. ${ }^{14}$ Thus, the central bank's constrained choice is characterized by two parameters introduced above, $\lambda$ and $\beta$. Restating the cross-equation restrictions in equation (4), we have: $b_{N N}=\lambda$, $b_{R N}=-(1-\lambda) \beta, b_{E N}=-(1-\lambda)(1-\beta)$. As discussed below, these parameters can be estimated directly with standard non-linear techniques. ${ }^{15}$

The first parameter, $\lambda$, reflects the central bank's decision to adjust monetary aggregates (reserves and domestic credit) versus prices (interest rates and/or exchange rates). If $\lambda=1$, the adjustment takes place entirely through quantities (fixed interest rates and exchange rates). By contrast, if $\lambda=0$, the adjustment takes place entirely through prices. For intermediate cases $0<\lambda<1$, the adjustment occurs in some combination.

The second parameter, $\beta$, measures how adjustment of prices is divided between interest rates and exchange depreciation. If $\beta=1$, the exchange rate is fixed and the entire adjustment falls on the interest rate; if $\beta=0$, the authority is targeting the interest rate and instead the exchange rate bears the entire adjustment (assuming $\lambda$ does not equal unity). For intermediate cases, $0<\beta<1$, the adjustment occurs in some combination.

Note that these parameters can be combined to form a single indicator of exchange rate flexibility: the product $(1-\lambda)^{*}(1-\beta)$ tells us what percent of a capital market shock is reflected in exchange rate movements. For example, if $(1-\lambda)^{*}(1-\beta)=1$, the exchange rate is freely floating in the sense that 100 percent of a capital account shock is reflected in exchange rate movements.

As a continuous indicator, this one provides more nuanced information than discrete categorizations (for example, (Reinhart, Rogoff, 2004)). Also, unlike Levy-Yeyati and Sturznegger (2005), this indicator incorporates both net purchases of reserves and interest rate intervention.

Note also that sterilized intervention can be identified in the model. The coefficient $b_{D N}$ is composed of two parameters, $\lambda \alpha$. This parameter may be thought of as a sterilization or offset coefficient. ${ }^{16}$ If $\lambda=1$ and $\alpha=1$, domestic credit flows fully offset or sterilize reserve flows.

\section{Empirical Results: Brazil, Mexico, and Turkey}

This section presents empirical results of the model for three emerging market countries, namely Brazil, Mexico, and Turkey. ${ }^{17}$ These results help address several issues. Section 3.1 examines the reactions by each country's central banks to capital account shocks $e_{N}$, in terms of both the impact multipliers (the elements of $\boldsymbol{B}^{\boldsymbol{m} \boldsymbol{m}}$ ) and

\footnotetext{
${ }^{14}$ One way to interpret $e_{N}$ is that it includes time-varying, unobservable elements like expected exchange depreciation and risk. Here, the shock has been normalized on reserves. While this normalization is arbitrary, it does conform to previous literature, including Calvo, Leiderman, and Reinhart (1993). Also, in the strictest sense, $e_{N}$ may imply some sort of quantity rationing, since capital market shocks are not fully contained in the interest rate.

${ }^{15}$ The same result may be obtained by restricting $b_{N N}$ equal to unity (as is more commonly done). In this case, the parameters uncovered from linear estimates would be: $\lambda=1+b_{R N} / \beta, \beta=b_{R N}\left(b_{E N}+b_{R N}\right)$.

${ }^{16}$ Older literature, notably (Kouri, Porter, 1974) also attempted to estimate such a parameter. For a more recent discussion of this issue, see (Kletzer, Spiegel, 1998).

${ }^{17}$ All estimates are performed with RATS package; SVAR estimates use the CVMODEL procedure.
} 
TABLE 1 Contemporaneous Central Bank Reponses $e_{N}$

\begin{tabular}{|c|c|c|c|c|c|}
\hline & Brazil & \multicolumn{2}{|c|}{ Mexico } & \multicolumn{2}{|c|}{ Turkey } \\
\hline & $\begin{array}{c}\text { Post-Real } \\
\text { Managed } \\
\text { Float }\end{array}$ & $\begin{array}{c}\text { Pre- } \\
\text { Crisis, } \\
\text { Low } \\
\text { Inflation }\end{array}$ & $\begin{array}{l}\text { Post- } \\
\text {-Crises }\end{array}$ & $\begin{array}{l}\text { First } \\
\text { Period }\end{array}$ & $\begin{array}{l}\text { Second } \\
\text { Period }\end{array}$ \\
\hline & $\begin{array}{l}1994: 8- \\
-1998: 12\end{array}$ & $\begin{array}{l}1988: 1- \\
-1994: 10\end{array}$ & $\begin{array}{l}1995: 1- \\
-2000: 12\end{array}$ & $\begin{array}{c}1987: 1- \\
-1993: 12\end{array}$ & $\begin{array}{l}1994: 5- \\
-2001: 1\end{array}$ \\
\hline $\begin{array}{l}\text { Central Bank response to } e_{N} \\
\text { Quantities vs. Prices } \lambda\end{array}$ & $\begin{array}{c}\mathbf{0 , 8 0} \\
(0,05)\end{array}$ & $\begin{array}{c}1,02 \\
(0,01)\end{array}$ & $\begin{array}{c}\mathbf{0 , 7 8} \\
(0,09)\end{array}$ & $\begin{array}{c}\mathbf{0 , 7 8} \\
(0,18)\end{array}$ & $\begin{array}{c}\mathbf{0 , 5 4} \\
(0,09)\end{array}$ \\
\hline Internal Rate vs. Exchange Rate $\beta$ & $\begin{array}{c}\mathbf{0 , 9 0} \\
(0,04)\end{array}$ & $\begin{array}{l}-0,81 \\
(1,04)\end{array}$ & $\begin{array}{c}\mathbf{0 , 5 5} \\
(0,15)\end{array}$ & $\begin{array}{c}0,72 \\
(0,91)\end{array}$ & $\begin{array}{c}\mathbf{0 , 8 7} \\
(0,07)\end{array}$ \\
\hline $\begin{array}{l}\text { Overall Exch. Rat. Flexibility } \\
(1-l)^{*}(1-b)\end{array}$ & 0,02 & - & 0,10 & - & 0,06 \\
\hline Dom. Credit $\alpha$ & $\begin{array}{c}1,24 \\
(0,19)\end{array}$ & $\begin{array}{c}0,17 \\
(0,38)\end{array}$ & $\begin{array}{c}0,05 \\
(0,53)\end{array}$ & $\begin{array}{c}0,54 \\
(0,32)\end{array}$ & $\begin{array}{c}0,54 \\
(0,11)\end{array}$ \\
\hline $\begin{array}{l}\text { Variance Ratio Statistic: } \\
\operatorname{var}\left(e_{N}\right) /[\operatorname{var}(N)+\operatorname{var}(R)+\operatorname{var}(E)]\end{array}$ & 0,27 & 0,16 & 0,20 & 0,08 & 0,06 \\
\hline
\end{tabular}

Note: Boldface indicates estimate is statistically different from zero at 90 percent level or higher.

Standard errors in parentheses.

the dynamic responses (through impulse response functions). Section 3.2 examines the impact of capital account shocks on three domestic variables: output growth, inflation, and the primary fiscal deficit.

For each country, the results are presented for selected subperiods that reflect distinct and well-known policy regimes. ${ }^{18}$ For Mexico, we divide the sample period into two subperiods: (i) the low-inflation, managed exchange rate period before the Tequila crisis (1988:1-1994:10), and (ii) the post-crisis period, including the float (1995:1-2000:12).

Similarly, for Turkey, the two periods are separated by an exchange rate crisis, namely (i) 1987:1-1993:12 period and (ii) 1994:5-2001:1 period. For Brazil, we have sufficient data for only one period: the Post-Real managed float/exchange rate band era (1994:8-1998:12). All variables are stationary. Results of both unit root tests and the reduced form of the VAR system (1) are available upon request.

\subsection{Central Bank Reactions}

Table 1 presents point estimates of the impact multipliers of foreign reserve accumulation, interest rate changes, and exchange depreciation for capital account shocks $e_{N}$ : the parameters $\lambda, \beta$ and $\alpha$. The last row of Table 1 presents the variance ratio statistic given by $\operatorname{var}\left(e_{N}\right) /[\operatorname{var}(N)+\operatorname{var}(R)+\operatorname{var}(E)]$. This statistic indicates informally how important are capital account shocks in explaining the total variability of the components of exchange market pressure $(N, R$ and $E) .{ }^{19}$

The dynamic responses of three key variables are summarized by impulse responses (IRF's) in Figures 1 through 3, where solid lines indicate the response while

${ }^{18}$ Mexico, widely studied by other authors (Calvo and Mendoza (1985), Edwards and Savastano (1998), and Khamis and Leone (2001)) is the reference case and hence discussed first.

${ }^{19}$ An alternative measure $\operatorname{var}\left(e_{N}\right) / \operatorname{var}(N+R+E)$ yielded similar results. 
FIGURE 1 Mexico: Impulse Responses to $e_{N}$, Monetarray Variables

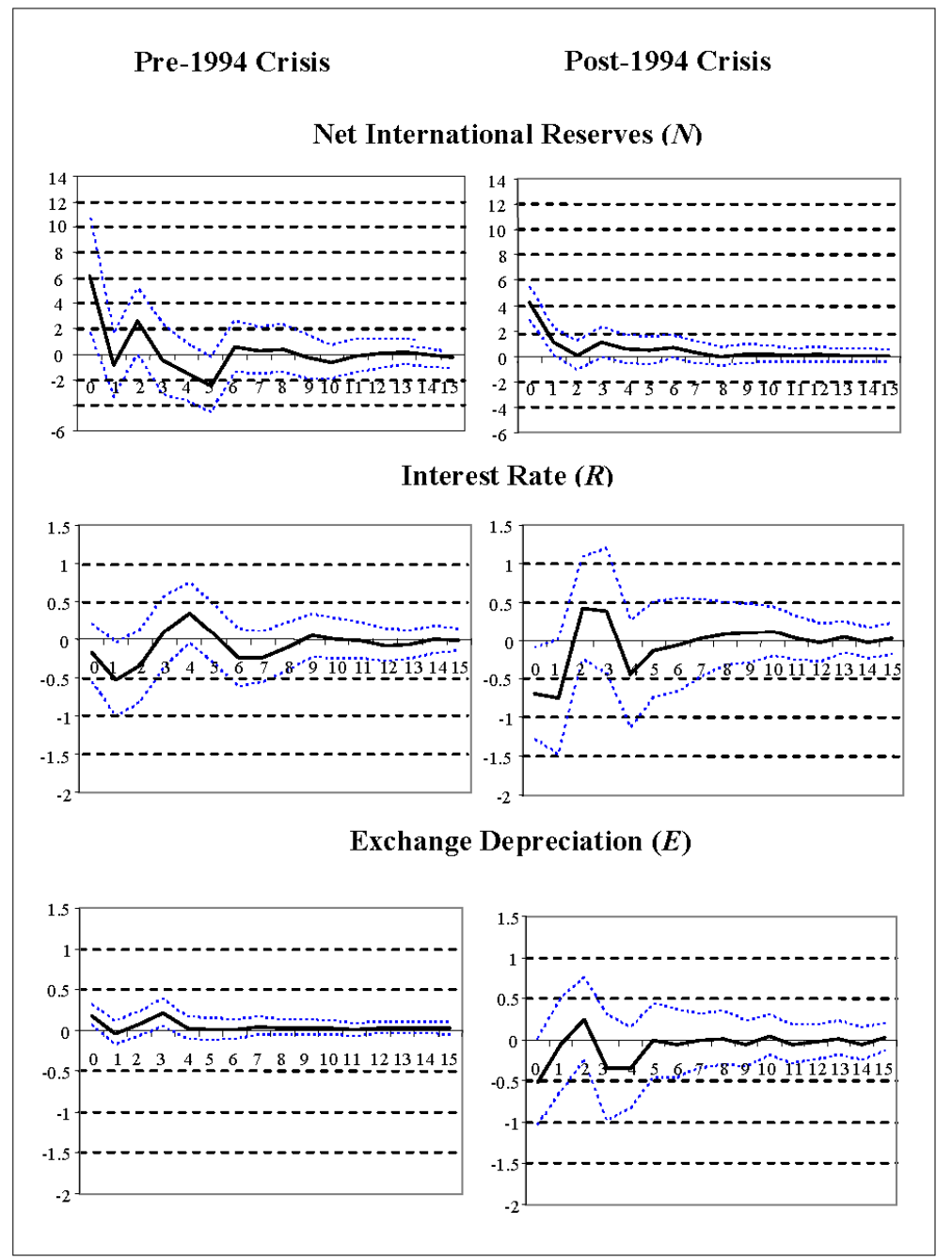

Note: Dotted lines indicate 90 percent confidence bands (1.65times standard error)

dotted lines indicate 90 percent probability bands. ${ }^{20}$ Where appropriate, axes use common scales. The impact multipliers results confirm that all three countries intervene in exchange markets: in all cases, $\lambda$ is statistically different from zero; the lowest value is found in Turkey's late period where $\lambda=0.54$.

According to the variance ratio statistic, $\operatorname{var}\left(e_{N}\right) /[\operatorname{var}(N)+\operatorname{var}(R)+\operatorname{var}(E)]$, across countries and time periods, the shocks $e_{N}$ account for varying proportions of

${ }^{20}$ A 90percent confidence band is equivalent to \pm 1.65 times the standard error (see, for example (Kim, 2003)). Standard errors are calculated in RATS by the Monte Carlo algorithm due to Kloek and van Djik (1978). 
FIGURE 2 Brazil: Impulse Responses to $e_{N}$, Monetary Variables

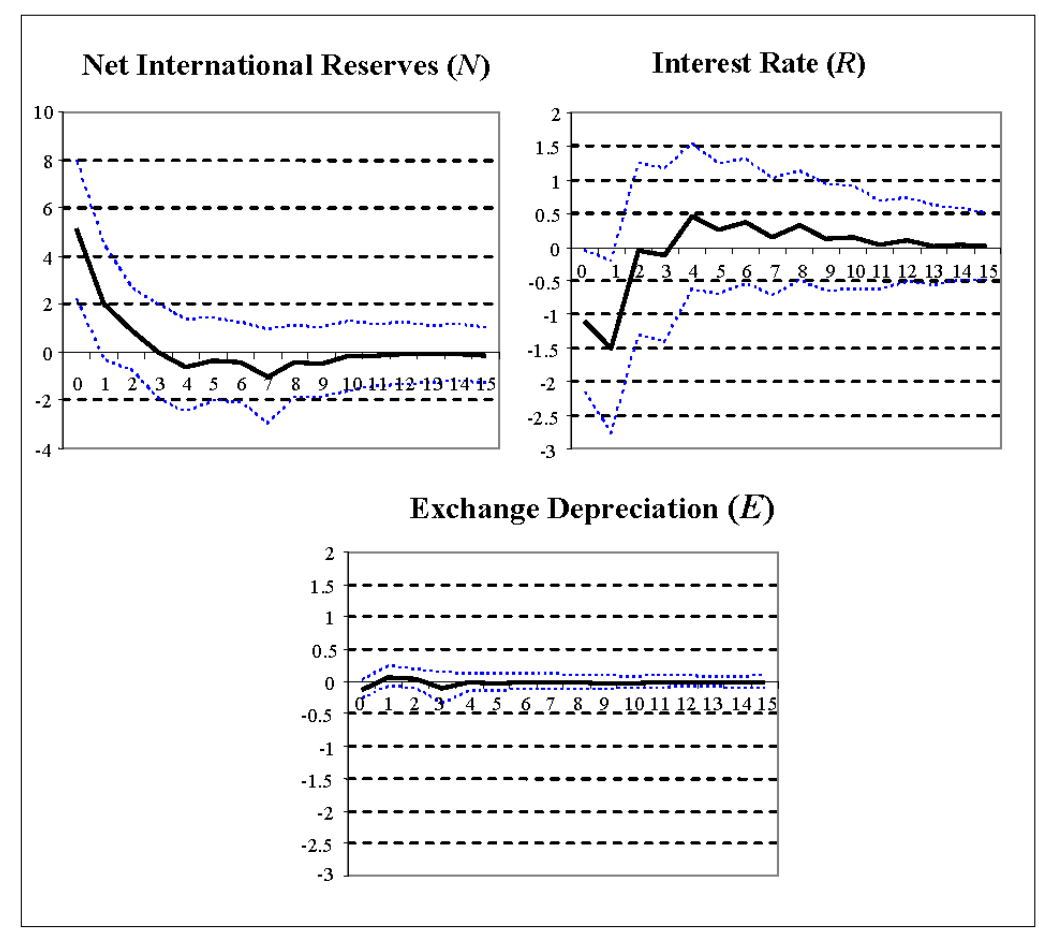

Note: Dotted lines indicate 90 percent confidence bands (1.65times standard error)

the exchange market pressure variables $(N, R$ and $E)$. In Brazil, this statistic indicates that $e_{N}$ explains about 27 percent of the total variance; in Mexico's pre- and post-crisis periods, these figures are about 16 and 20 percent; for Turkey's early and later periods, these figures are about 8 and 6 percent, respectively.

The case where the authorities were least willing to adjust either interest rates or exchange rates is Mexico prior to the 1994 crisis. Here, $\lambda$ is estimated to be 1.02 but not statistically different from unity, suggesting that the central bank in Mexico responded to an adverse shock mostly by sales or purchases of international reserves. ${ }^{21}$

However, after the 1994 crisis, Mexico's policy changed. The estimate of $\lambda$ falls to 0.78 (statistically different from zero). Thus, relative to the pre-crisis period, the authority was more willing to permit price movements (interest rates, exchange rates or both) to adjust in response to an external shock. Note also that $\beta$ is estimated to be 0.55 (significantly different from zero). This suggests that the remaining portion of the shock - that not absorbed by reserve movements - was distributed almost equally between interest rate and exchange rate movements. As in the pre-crisis period, the IRF for the post-crisis period (Figure 1, right-hand column) reveals a significant negative interest rate response at one lag. Note finally that, according to the over-

${ }^{21}$ However, the IRF reveals a small but statistically significant negative reaction of the interest rate at the first lag. 
FIGURE 3 Turkey: Impulse Responses to $e_{N}$, Monetary Variables

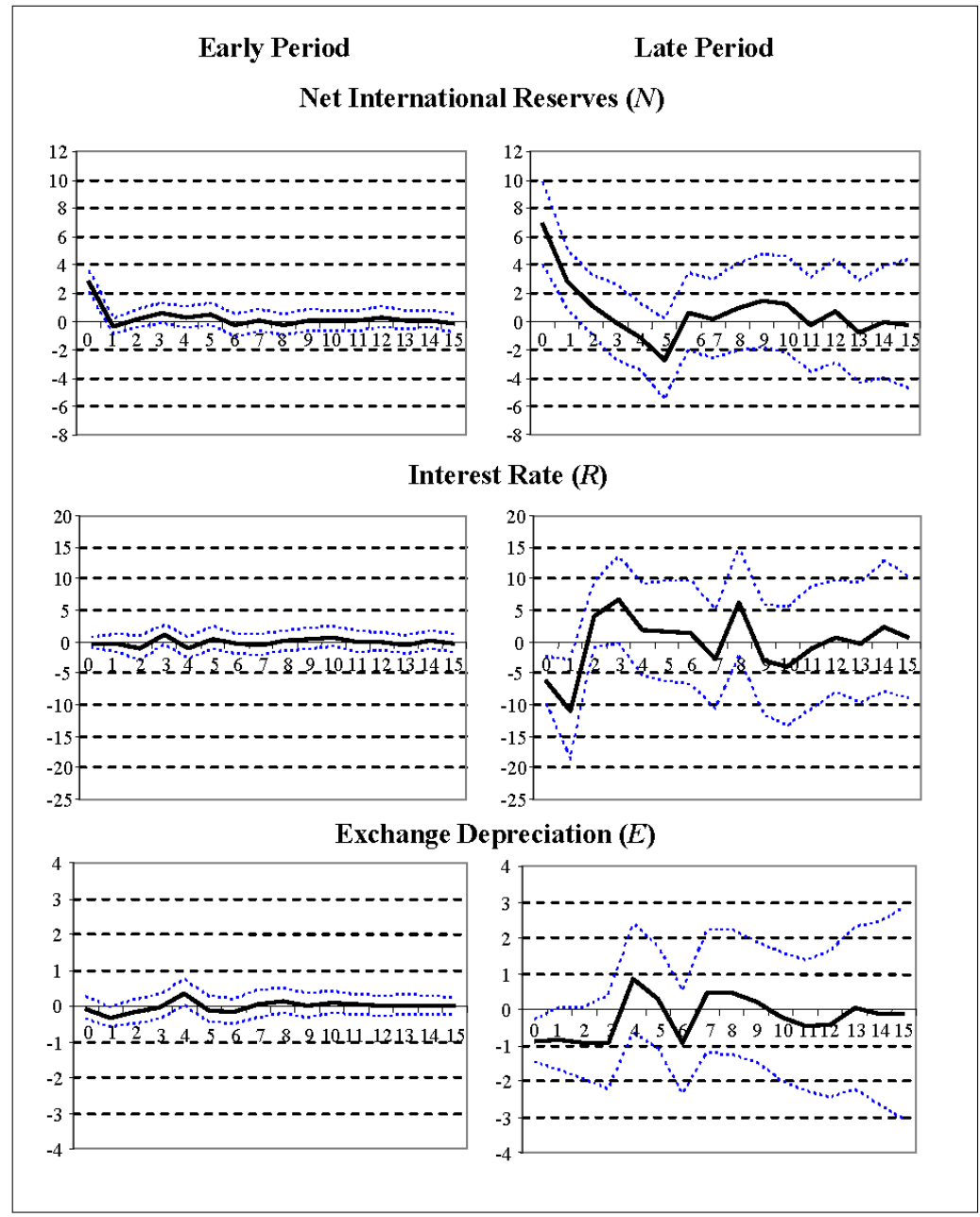

Note: Dotted lines indicate 90 percent confidence bands (1.65times standard error)

all indicator of exchange rate flexibility $(1-\lambda) *(1-\beta)$, the exchange rate absorbed 0 percent of a capital account shock prior to the 1994 crisis but about 10 percent afterwards. These results confirm Edwards and Savastano's (1998) conclusion that the Mexican central bank managed exchange rates, both before and after the 1994 crisis.

For Brazil's managed float period, the authorities were slightly more willing to permit price adjustments than in post-crisis Mexico $(\lambda=0.80$, statistically different from zero). At the same time, the authorities appear to be more willing to use the interest rate than in Mexico: the parameter $\beta$ is estimated to be 0.90 (statistically different from zero). The IRFs in Figure 2 also reveal a statistically significant negative response of interest rate changes at one lag. According to the overall indicator of 
exchange rate flexibility $(1-\lambda) *(1-\beta)$, the exchange rate absorbed about 2 percent of a capital account shock.

In Turkey, as in Mexico, there is a striking contrast in central bank policy between the early and later periods. In the early period, the authority seemed less willing to permit immediate price adjustments $(\lambda=0.93$, significant) than in the later ( $\lambda=0.54$, significant). However, according to the IRF in Figure 3, there is a negative response at the first lag during the earlier period, but no response (contemporaneous or lagged) during the later period. Note also that the authority relies less on interest rate adjustments in the earlier period $(\beta=0.72$, not significant) than in the latter $(\beta=0.87$, significant). And, the IRF's also reveal a negative impact on interest rate changes at one lag for the later period. Note finally that, according to the overall indicator of exchange rate flexibility $(1-\lambda)^{*}(1-\beta)$, the exchange rate absorbed about 6 percent of a capital account shock in both periods (although $\beta$ is significant only in the latter).

\subsection{The Transmission of Capital Account Shocks $e_{N}$ to the Domestic Economy}

One reason why authorities choose a particular exchange rate regime is that they wish to shield the domestic economy from external shocks, especially capital account shocks $\left(e_{N}\right)$.

Accordingly, we now investigate how capital account shocks $\left(e_{N}\right)$ are transmitted to key domestic variables: the growth of economic activity $(Y)$ and inflation $(P)$ by examining the impulse response functions. ${ }^{22}$

The outcome should depend on the exchange rate regime. For example, if the central bank reduces exchange rate flexibility by raising $\beta$ (permitting more interest rate flexibility), the IRF should reveal larger impacts of $e_{N}$ on output, through the interest rate channel. Likewise, if $\beta$ rises, the IRF should also reveal a smaller impact of $e_{N}$ on inflation, through the exchange rate pass-through channel.

Figures 4 and 5 present the responses of $Y$ and $P$ to capital account shocks $e_{N}$ for Mexico and Turkey, respectively. ${ }^{23}$ Evidence presented below suggests capital account shocks often have significant impacts on the domestic economy.

Consider first the effects of $e_{N}$ on output growth $(Y)$ in Mexico (Figure 4, first row). In the pre-crisis period, there is no statistically significant impact of $e_{N}$ on $Y$. By contrast, there is statistically significant impact of $e_{N}$ on $Y$ - with a three month lag - in the post-crisis period.

These findings support the idea that the exchange rate regime affects the transmission of capital market shocks to the domestic economy. The central bank did not permit interest rates to respond to capital account shocks in the pre-crisis period, but did so in the post-crisis period. Thus, stabilizing the exchange rate through interest rate movements (as happened in the post-crisis period) may have made output growth more positively related to capital account shocks and more volatile than it otherwise would have been. However, such an explanation must be viewed cautiously. An alternative explanation, that the structure of the economy might have changed, should not be immediately discarded.

\footnotetext{
${ }^{22}$ In an earlier version of this paper (available upon request) we also examine the effect of $e_{N}$ shocks on the primary fiscal balance $(F)$.

${ }^{23}$ These results are not presented for Brazil, since there were no significant IRFs.
} 
FIGURE 4 Mexico: Impulse Responses to $e_{N}$, Nonmonetary Variables

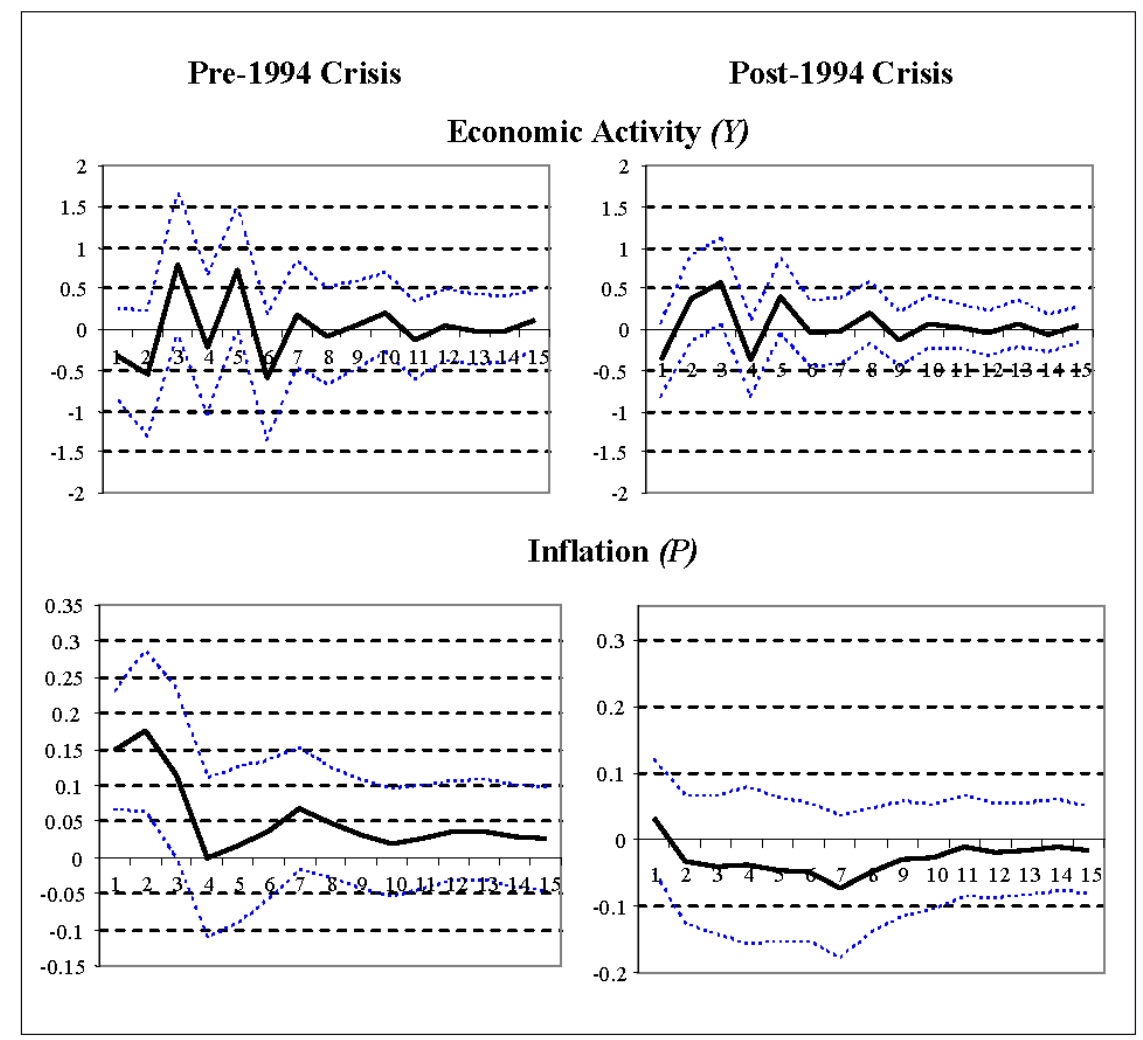

Note: Dotted lines indicate 90 percent confidence bands (1.65times standard error)

Next note the effects of $e_{N}$ on inflation in Mexico (Figure 4, second row). In the pre-crisis period, when exchange rates were tightly pegged, shocks to $e_{N}$ had a positive impact on inflation. By contrast, under a fixed exchange rate system (or a band) capital inflows $\left(e_{N}>0\right)$ are generally associated with an appreciation of the real exchange rate.

These empirical results are also broadly consistent with the general presumption of how the exchange rate regime affects the transmission of capital market shocks to the domestic economy. In the pre-crisis, fixed exchange rate period, the appreciation takes place through (the nontradable component of) domestic inflation. However, in the post-crisis period, when exchange rates were more flexible, the real appreciation instead took place through a nominal appreciation. This reduces inflation through the tradable goods component.

We now turn to responses for Turkey, which are presented in Figure 5. As in Mexico, behavior of output growth ( $Y$, Figure 5, first row) differs across exchange rate regimes. In the early period, when $e_{N}$ is primarily channeled by the central bank to reserve flows (high $\lambda, \beta$ not significant), $e_{N}$ also impacts output positively and significantly after four months. ${ }^{24}$ 
FIGURE 5 Turkey: Impulse Responses to $e_{N}$, Non-monetary Variables

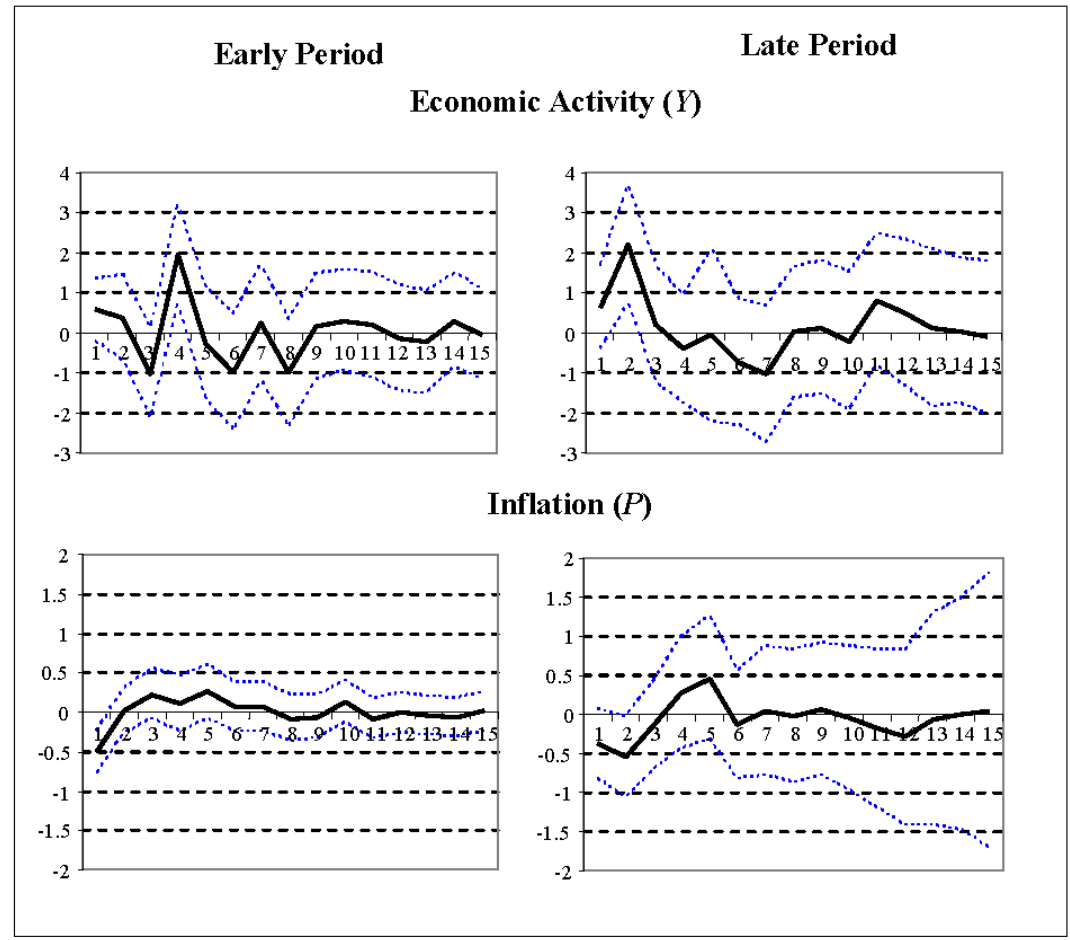

Note: Dotted lines indicate 90 percent confidence bands (1.65times standard error)

Note that in the later period, the positive impact of $e_{N}$ on $Y$ occurs sooner (two months later rather than four) and is somewhat greater in magnitude. This finding may reflect the more active interest rate policy during this period (lower $\lambda$; higher, significant $\beta$ ).

The second row of Figure 5 shows the responses of inflation $(P)$ to $e_{N}$ shocks. Unsurprisingly, inflation mirrors the exchange rate regime. In the early period, there is a negative and significant impact of $e_{N}$ on inflation at lag one. This corresponds precisely to the impact of $e_{N}$ on exchange depreciation $(E)$ at this same lag mentioned in the previous section. By contrast, in the second period, there are no significant impacts of $e_{N}$ on inflation $(P)$ - or for exchange depreciation $(E)$.

\section{What if the Exchange Rate Had Been More (or Less) Flexible? A Counterfactual Analysis}

In the latter half of the 1990 s, the countries included in this paper faced some similar considerations in their choice of exchange rate regime. Brazil and Mexico both desired to restrain inflation under their relatively young stabilization plans,

${ }^{24}$ A possible explanation for this finding might be credit rationing: capital outflows cause tightening in credit markets (but not directly through interest rates). 
while Turkey was attempting a more dramatic disinflation. At the same time, all countries sought to limit the adverse effects of global shocks on domestic economic activity. Nonetheless, in the aftermaths of exchange rate crises, Mexico and Turkey relied less on reserve movements (lower $\lambda$ ) but more on interest rate movements (higher $\beta$ ) to manage exchange rates. ${ }^{25}$

A counterfactual question naturally arises: how would inflation and output have behaved in these countries if the central bank had chosen a different exchange rate regime - different values for $\lambda$ and $\beta$ ?

The analysis in the previous section indirectly addresses this question. However, the question may be more directly addressed by simulating impulse response functions (IRFs) associated with counterfactual values for $\lambda$ and $\beta$. Such an IRF shows by how much the impact of a shock $e_{N}$ on other variables would have changed had the exchange rate regime (summarized by $\lambda$ and $\beta$ ) been different. Of course, an analysis of this nature should be regarded as useful but only suggestive. Market participants may change their decision rules - and thus system dynamics - in response to changes of $\lambda$ and/or $\beta$. $^{26}$

For Brazil and Turkey, we simulate a policy of increased exchange rate flexibility by reducing $\beta$. For Mexico, we simulate policies of both increasing and decreasing exchange rate flexibility by raising and lowering $\beta$. Similar experiments with $\lambda$ were conducted but not reported here. For Mexico and Turkey, the analysis uses data from only the more recent periods. ${ }^{27}$

Counterfactual IRFs for output and inflation are presented in Figures 6 and 7, respectively. Results for output (Figure 6) were mixed. Presumably, in the case of an adverse shock (symmetric for positive), a less positive response function would be expected when $\beta$ is reduced. An interest rate hike is the outcome of an adverse shock and is presumed to reduce growth. Thus, lower $\beta$ means a lower interest rate hike and an accordingly lower output drop. ${ }^{28}$ For Brazil and Turkey (but not Mexico) this result is observed, but only for later lags, and only after observing a more positive response in the initial periods. ${ }^{29}$ Thus, these results suggest that more exchange rate flexibility (lower $\beta$ ) means more variable output growth in the initial stages, but less

\footnotetext{
${ }^{25}$ The tests show this relation for Mexico and Turkey. This is also true for Brazil in 1999 and afterwards, although we did not estimate parameters for this time period due to insufficient data.

${ }^{26}$ That is, this analysis should be regarded only as suggestive since it may be subject to the "Lucas critique."

${ }^{27}$ In both Mexico and Turkey, the later periods were ones of relative exchange rate flexibility. However, for Mexico, the estimated $\beta$ is about 0.55 (see Table 1). Counterfactual exchange rate regimes are $\beta=0.3$ (more flexible) and $\beta=0.7$ (less flexible). By contrast, for Turkey, the estimate of $\beta$ was higher - about 0.9 . The counterfactual exchange rate regimes are $\beta=0.7$ and $\beta=0.3$ (both more flexible). For Brazil, the central bank defended the exchange rate within a narrow, moving band, with $\beta$ estimated to be about 0.9 . Counterfactual exchange rate regimes of $\beta=0.7$ and $\beta=0.5$ both would be consistent with a widening of the band.

${ }^{28}$ Note that this interpretation is consistent with the idea that, as exchange rate are more flexible, so are real wages, thus reducing output variability.

${ }^{29}$ In the case of Brazil (Figure 6, top panel), impacts on output growth for lags 1 and 2 exceed those in the baseline. But, at later lags, more exchange rate flexibility appears to make output somewhat less variable, relative to the baseline. Likewise, for Turkey (Figure 7, bottom panel), impact on output growth a lags 4 through 6 exceed those in the baseline.
} 
FIGURE 6 Simulated Responses of Output Growth $(Y)$ to Schock $e_{N}$ : Estimated Versus Counterfactual Values of $\beta$

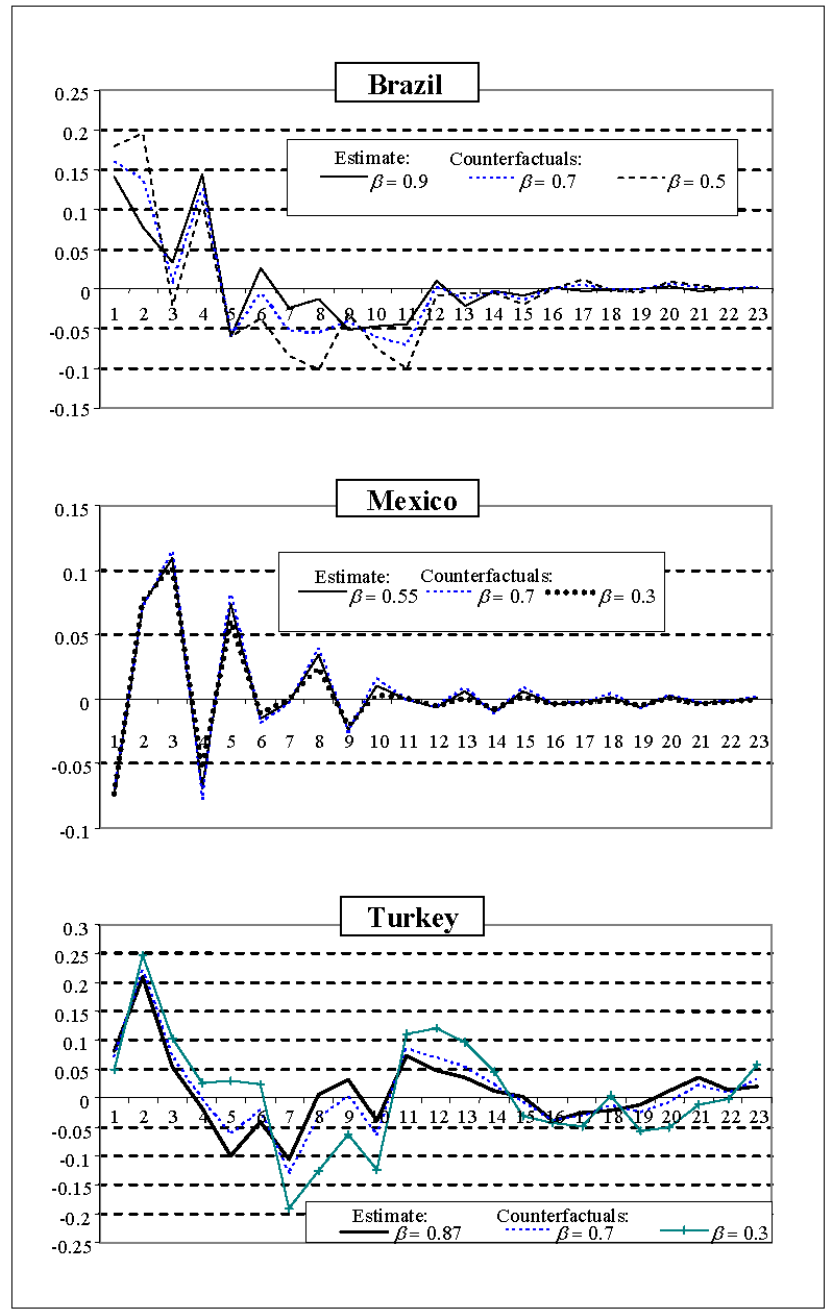

Source: author's own estimates

so at later lags. Note that, for Mexico, even as $\beta$ was raised or lowered dramatically, the impact of $e_{N}$ on output growth was largely unchanged.

The results for inflation (Figure 7) were stronger than those for output, with few surprises. As the exchange rate regime became more flexible (lower $\beta$ ), the link between $e_{N}$ and inflation became unambiguously stronger and more negative. This occurs after the first lag in Brazil and Turkey, but only after the second lag for Mexico. These effects indicate additional transmission of exchange rate depreciation to domestic inflation.

With more flexible exchange rates (lower $\beta$ ), when any of these countries suffers an adverse capital account shock, they will also suffer higher inflation, in all 
FIGURE 7 Simulated Responses of Inflation $(P)$ to Schock $e_{N}$ : Estimated Versus Counterfactual Values of $\beta$

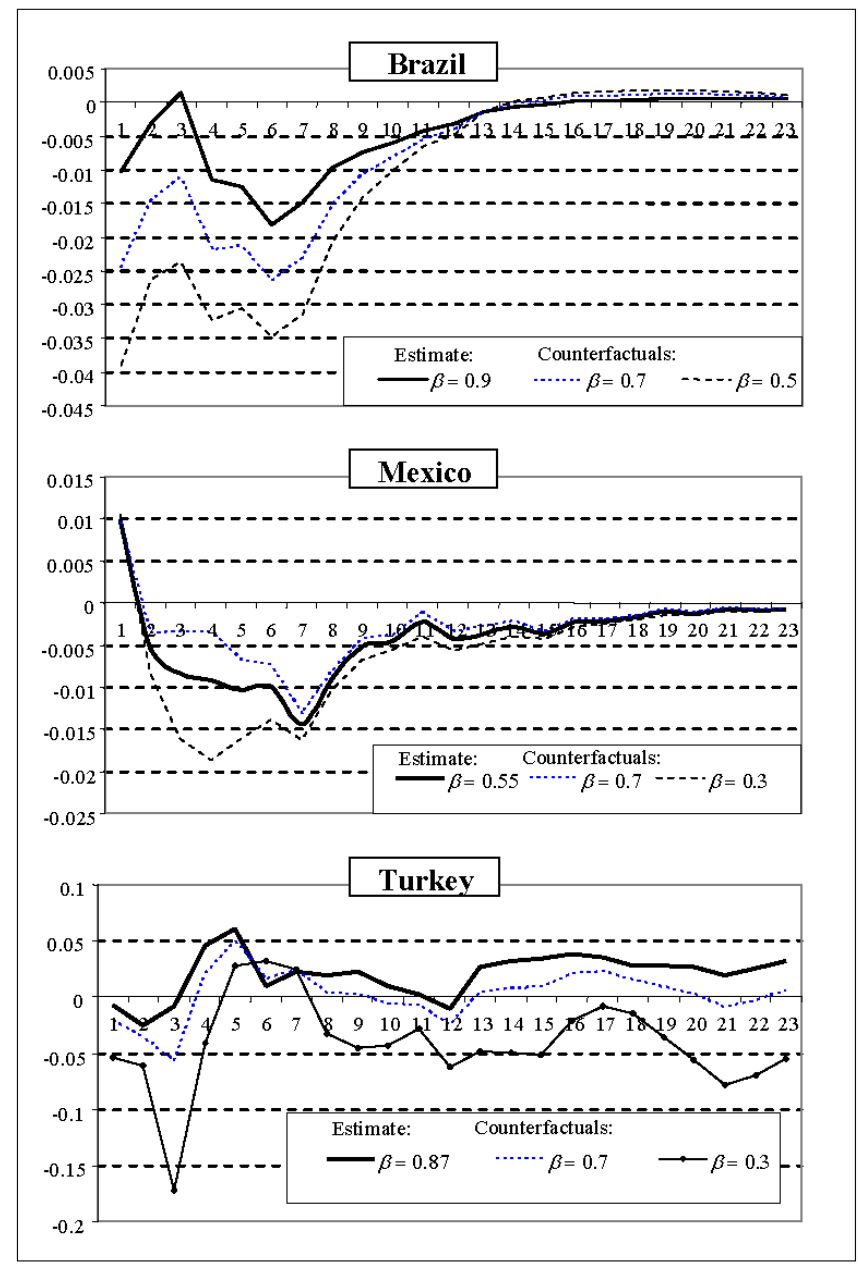

Source: author's own estimates

periods. However, the costs in terms of output loss are ambiguous: the country suffers somewhat lower output loss in the initial periods, but not necessarily in subsequent periods.

The results in this section therefore strongly suggest that, if transmitted through the exchange rate, capital account shocks affect inflation. This is often called exchange rate "pass-through". If such shocks are instead transmitted to interest rates, such pass-through is substantially reduced. 


\section{Summary and Conclusions}

This paper examined the choice of an exchange rate regime and its effects on growth and inflation in three emerging market economies, namely Brazil, Mexico, and Turkey. Using a structural vector autoregression approach, we empirically characterized a country's exchange rate regime as a dynamic response to capital account shocks - how these countries "pick their poison." We then analyzed the "poison" itself, namely the effect of such shocks on two key domestic variables: real economic growth and inflation, conditional on an exchange rate regime chosen by the central bank. The paper thus makes two contributions.

First, the paper illustrated a number of ways that countries may "pick their poison". In pre-1994 crisis Mexico, capital account shocks were entirely reflected in reserve flows. After the crisis, the central bank permitted about 78 percent of such shocks to be transmitted to reserve flows, 12 percent to interest rates, and 10 percent to exchange rates. At the other extreme, in Turkey's later period, the central bank permitted about 54 percent of such shocks to be transmitted to reserve flows, 40 percent to interest rates, and 6 percent to exchange rates. The approach yielded an indicator to gauge a country's exchange rate regime that has several advantages over the extant indices.

Second, the paper reiterates some policy conclusions regarding the choice of exchange rate regime. Results suggested that capital account shocks can have a substantial impact on inflation and growth. The nature and magnitude of the impact depends on the exchange rate regime. Our results indicate that when capital account shocks are channeled into the exchange rate, they substantially affect inflation. If instead such shocks are channeled to the interest rate, such exchange rate pass-through effects are substantially mitigated. Doing so may entail a trade-off: interest rate movements may instead be transmitted to output. However, evidence regarding output effects is somewhat less compelling than that for inflation itself.

\section{Data Construction}

Variables were constructed as follows:

1. Industrial production growth $(Y)$ : monthly percentage change in industrial production index. Source: country central banks.

2. Terms of trade growth $(T)$ : Brazil, Mexico, monthly percent change in ratio of export prices to import prices. Turkey: monthly percent change in petroleum prices.

3. Interest rate, first difference $(R)$ : Brazil: money market rate (series 60 b.z); Mexico: banker's acceptance rate (series 60 b.z); Turkey: interbank rate (series 60 b.z); Source: International Monetary Fund, International Financial Statistics.

4. Monetary base: Source: International Monetary Fund, International Financial Statistics, Reserve Money (series 14).

5. Exchange rate, end of period, period average: International Monetary Fund, International Financial Statistics, reserve money (series ae and rf respectively). 
6. Net foreign reserves $(N)$; change with respect to previous month, divided by monetary base of previous month. Level of net foreign assets is from International Monetary Fund, International Financial Statistics, (series 11 minus series 16).

7. Net domestic credit $(D)$; change with respect to previous month, divided by monetary base of previous month. Level of net foreign assets is from International Monetary Fund, International Financial Statistics, (series 14 minus 11 plus series 16).

8. Fiscal deficit $(F)$ : primary deficit scaled by monetary base. Source: country central banks.

\section{REFRENCES}

Blustein P (2001): The Chastening: Inside the Crisis that Rocked the Global Financial System and Humbled the IMF. New York, Public Affairs Press.

Bubula A, Otker-Robe I (2002): The Evolution of Exchange Rate Regimes Since 1990: Evidence from de facto Policies. IMF Working Paper, no. 02/155.

Calvo G, Leiderman L, Reinhart C (1993): Capital Inflows and Real Exchange Rate Appreciation in Latin America: The Role of External Factors. Staff Papers, International Monetary Fund, 40(1-March): 108-51.

Calvo G, Mendoza E (1996): Mexico's Balance-of-Payments Crisis: A Chronicle of a Death Foretold. Journal of International Economics, 41:235-64.

Cushman D, Zha T (1997): Identifying Monetary Policy in a Small Open Economy under Flexible Exchange Rates. Journal of Monetary Economics, 39, (3-August):433-48.

Edwards S. (1999): Exchange Rates in Emerging Economies: What Do We Know? What Do We Need to Know? NBER Working Paper, no. 7228 (Cambridge, Massachusetts: National Bureau of Economic Research).

Edwards S (2000): Capital Flows, Real Exchange Rates, and Capital Controls: Some Latin American Experiences. In: (Ed.: S. Edwards): Capital Flows and the Emerging Economies: Theory, Evidence, and Controversies. Chicago and London, University of Chicago Press.

Edwards S, Savastano S (1998): The Morning After: The Mexican Pesoin the Aftermath of the 1994 Currency Crisis. NBER Working Paper, 6516 (Cambridge, Massachusetts: National Bureau of Economic Research).

Eichengreen B, Rose A, Wyplosz C (1996): Contagious Currency Crises: First Tests. Scandinavian Journal of Economics, 98(4):463-84.

Fernandez-Arias E (1996): The New Wave of Private Capital Inflows: Push or Pull? Journal of Development Economics, 48(2-March):389-418.

Fischer S (2001): Exchange Rate Regimes: Is the Bipolar View Correct? Speech delivered at the Meetings of the American Economic Association. Available on the Internet at:

http://www.imf.org/external/np/speeches/2001/010601a.htm

Girton L, Roper D (1977): A Monetary Model of Exchange Market Pressure Applied to the Postwar Canadian Experience. American Economic Review, 67(4):537-48.

Khamis M, Leone A (2001): Can Currency Demand Be Stable Under a Financial Crisis? The Case of Mexico. IMF Staff Papers, 48(2):344-66.

Kim S (2001): International Transmission of U.S. Monetary Policy Shocks: Evidencefrom VAR's. Journal of Monetary Economics, 48(2-October):339-72.

Kim S (2003): Monetary Policy, Foreign Exchange Intervention, and the Exchange Rate in a Unifying Framework. Journal of International Economics, 60(2):355-86. 
Kim S, Roubini N (2000): Exchange Rate Anomalies in the Industrial Countries: A Solution with a Structural VAR Approach. Journal of Monetary Economics, 45(3-June):561-86.

Kletzer K, Spiegel M (1998): Speculative Capital Inflows and Exchange Rate Targeting in the Pacific Basin: Theory and Evidence. In: (Ed.: Reuven Glick) Managing Capital Flows and Exchange Rates: Perspectives from the Pacific Basin. Cambridge, New York, Melbourne: Cambridge University Press.

Kloek T, van Dijk HK (1978): Bayesian Estimates of Equation System Parameters: An Application of Integration by Monte Carlo. Econometrica, 46(1):1-19.

Kouri PJK, Porter MG (1974): International Capital Flows and Portfolio Equilibrium. Journal of Political Economy, 82(3-May/June):443-67.

Lahiri A, Végh C (2001): Living with the Fear of Floating: An Optimal Policy Perspective. NBER Working Paper, no. 8391 (Cambridge, Massachusetts: National Bureau of Economic Research).

Levy-Yeyati E, Sturzenegger F (2005): Classifying Exchange Rate Regimes: Deeds vs. Words. European Economic Review, 49(6-August):1603-35

Parrado E, Velasco A (2002): Optimal Interest Rate Policy in a Small Open Economy. NBER Working Paper, no. 8721.

Reinhart C, Rogoff K (2004):The Modern History of Exchange Rate Arrangements: A Reinterpretation. Quarterly Journal of Economics, 119(1-February):1-48 .

Sachs J, Tornell A, Velasco A (1996): Financial Crises in Emerging Markets: The Lessons from 1995. Brookings Papers on Economic Activity: 1:147-215.

Tanner E (2000): Exchange Market Pressure and Monetary Policy: Asia and Latin America in the 1990s. IMF Staff Papers, 47(3):311-33. 